\title{
Combined common peroneal and tibial nerve injury after knee dislocation: one injury or two? An MRI-clinical correlation
}

\author{
Chandan G. Reddy, MD, ${ }^{1}$ Kimberly K. Amrami, MD, ${ }^{2,3}$ Benjamin M. Howe, MD, ${ }^{3}$ and \\ Robert J. Spinner, MD²
}

${ }^{1}$ Department of Neurosurgery, University of lowa Carver College of Medicine, lowa City, lowa; and Departments of ${ }^{2}$ Neurologic Surgery and ${ }^{3}$ Radiology, Mayo Clinic, Rochester, Minnesota

\begin{abstract}
OBJECT Knee dislocations are often accompanied by stretch injuries to the common peroneal nerve (CPN). A small subset of these injuries also affect the tibial nerve. The mechanism of this combined pattern could be a single longitudinal stretch injury of the CPN extending to the sciatic bifurcation (and tibial division) or separate injuries of both the CPN and tibial nerve, either at the level of the tibiofemoral joint or distally at the soleal sling and fibular neck. The authors reviewed cases involving patients with knee dislocations with CPN and tibial nerve injuries to determine the localization of the combined injury and correlation between degree of MRI appearance and clinical severity of nerve injury.

METHODS Three groups of cases were reviewed. Group 1 consisted of knee dislocations with clinical evidence of nerve injury ( $n=28$, including 19 cases of complete CPN injury); Group 2 consisted of knee dislocations without clinical evidence of nerve injury ( $n=19)$; and Group 3 consisted of cases of minor knee trauma but without knee dislocation ( $n$ = 14). All patients had an MRI study of the knee performed within 3 months of injury. MRI appearance of tibial and common peroneal nerve injury was scored by 2 independent radiologists in 3 zones (Zone I, sciatic bifurcation; Zone II, knee joint; and Zone III, soleal sling and fibular neck) on a severity scale of 1-4. Injury signal was scored as diffuse or focal for each nerve in each of the 3 zones. A clinical score was also calculated based on Medical Research Council scores for strength in the tibial and peroneal nerve distributions, combined with electrophysiological data, when available, and correlated with the MRI injury score.
\end{abstract}

RESULTS Nearly all of the nerve segments visualized in Groups 1 and 2 demonstrated some degree of injury on MRI (95\%), compared with $12 \%$ of nerve segments in Group 3. MRI nerve injury scores were significantly more severe in Group 1 relative to Group 2 (2.06 vs 1.24, $p<0.001$ ) and Group 2 relative to Group 3 (1.24 vs 0.13, p < 0.001). In both groups of patients with knee dislocations (Groups 1 and 2), the MRI nerve injury score was significantly higher for CPN than tibial nerve (2.72 vs 1.40 for Group 1, $p<0.001 ; 1.39$ vs 1.09 for Group 2, $p<0.05$ ). The clinical injury score had a significantly strong correlation with the MRI injury score for the CPN $(r=0.75, p<0.001)$, but not for the tibial nerve $(r=$ $0.07, p=0.83$ ).

CONCLUSIONS MRI is highly sensitive in detecting subclinical nerve injury. In knee dislocation, clinical tibial nerve injury is always associated with simultaneous CPN injury, but tibial nerve function is never worse than peroneal nerve function. The point of maximum injury can occur in any of 3 zones.

http://thejns.org/doi/abs/10.3171/2015.6.FOCUS15125

KEY WORDS foot drop; knee dislocation; MRI; nerve; peroneal; tibial

$\mathrm{K}$ NEE dislocations typically result from high-energy forces and frequently result in multiligamentous and neurovascular injury. Common peroneal nerve (CPN) palsy has been reported in $25 \%-40 \%$ of cases. ${ }^{4,5,10,15}$ The mechanism has been thought to be a stretch lesion to the posterolateral aspect of the knee. ${ }^{24}$ Because of the broad zone of injury seen clinically, patients often fare poorly and do not recover either spontaneously or even when treated with long interpositional grafts. Salvage procedures such as posterior tibialis tendon transfer may be necessary to eliminate the need for an ankle-foot orthosis.

On occasion, the same injury pattern may result in

ABBREVIATIONS BMI = body mass index; $\mathrm{CPN}=$ common peroneal nerve; EMG = electromyography; $\mathrm{KD}=$ knee dislocation (with reference to classification system); LCL = lateral collateral ligament; MRC = Medical Research Council. 
combined peroneal and tibial nerve injuries. The latter is almost always incomplete. Frequently, the tibial nerve lesions are subtle, such as seen with asymmetrical toe flexion on clinical examination or subtle changes on electromyography. In other cases, the tibial nerve deficit may be more profound, even eliminating the possibility of a functioning posterior tibialis transfer. The mechanism of the combined injury has been assumed by us, as well as others, to be due to longitudinal stretch from the posterolateral aspect of the knee affecting the CPN up to the sciatic bifurcation, including the tibial division. The tibial component, unless complete, usually is not addressed surgically.

Recently, the soleal sling has been introduced as a potential alternative site for proximal nerve compression of the tibial nerve, either as a site of entrapment or following trauma. We wondered whether the soleal sling could be identified as a secondary site of injury in these patients who sustained high-energy injury to the peroneal nerve but who had tibial nerve findings as well. This could suggest that decompression of the tibial nerve at the soleal sling might be helpful.

Alternatively, the tibial nerve could be secondarily injured at the knee joint itself.

In this paper, we reviewed MR images obtained in groups of patients with knee dislocations and CPN and tibial nerve injuries to determine the localization of the combined injury and the prevalence of subclinical nerve injury. MRI injury scores were correlated to clinical injury severity based on physical examination and electrodiagnostic studies, when available.

\section{Methods \\ Patient Selection}

Retrospective review of cases involving patients treated for knee dislocation or knee trauma at our institution between 2001 and 2012 was performed using a searchable database. This patient list was further refined to select patients who had an MRI performed within 3 months of injury. This study was performed under the oversight of the Mayo Clinic institutional review board.

Three groups of patients were selected. Group 1 consisted of patients with knee dislocations and clinical evidence of nerve injury $(n=28), 19$ of whom had complete CPN injury; Group 2 consisted of patients who had knee dislocations without clinical evidence of nerve injury (n $=19$ ); and Group 3 consisted of patients with minor knee trauma but without knee dislocation $(n=14)$.

\section{Clinical Characteristics}

The degree of clinical peroneal and tibial nerve injury was noted using the Medical Research Council (MRC) grading scale criteria. Further patient characteristics, including age, sex, mechanism and velocity of injury, body mass index (BMI), ligaments involved together with knee dislocation score (based on Schenck's anatomical classification of knee dislocations ${ }^{18}$ ), other injuries (including bony, cartilaginous, and vascular injuries), and electrodiagnostic results (when available), are provided in detail in Table 1 and summarized in Table 2.

\section{MRI Injury Score}

All patients had an MRI of the knee performed within 3 months of injury. In most cases, the MRI studies were performed as conventional joint examinations without contrast. All MRI examinations included axial T2-weighted images with fat suppression. The MRI appearance of the CPN and tibial nerve injury was scored in 3 zones by 2 fellowship-trained musculoskeletal radiologists with expertise in peripheral nerve imaging. The 3 zones were as follows: Zone I, sciatic bifurcation; Zone II, knee joint; and Zone III, soleal sling and fibular neck (Figs. 1-3). Injury severity was scored on a scale of 1 to 4 , with 4 being most severe. Each nerve was also given a letter designation for each of the 3 zones based on the appearance of the nerve (intact, transected, etc.) and T2 hyperintensity within the nerve compared with skeletal muscle (see Table 3 for MRI grading criteria and Table 4 for results based on assessment by the senior radiologist). Focal injury (F) was defined as appearing on only 1 imaging slice (less than $5 \mathrm{~mm}$ ) versus diffuse injury (D), which appeared on 2 or more contiguous slices (generally $1 \mathrm{~cm}$ or more). In cases in which the nerve was unrecognizable from injury, $\mathrm{R}$ was assigned (for rupture). In cases of normal-appearing nerve, $\mathrm{N}$ was assigned (for normal). In areas of scoring discordance, the scoring of the senior radiologist was taken as final.

\section{Clinical Score}

Based on patient presentation, a clinical score was devised using a combination of clinical MRC grading criteria for both tibial and peroneal nerve function and electrodiagnostic evidence, when available, with electromyography and nerve conduction studies. The clinical grading scale ranged from -4 to +4 (with +4 being the most severe nerve injury; see Table 3 for precise grading criteria factoring into the clinical score).

Patients with normal clinical function of both nerves received a score of -4 . Those with incomplete $\mathrm{CPN}$ injury received a score between -3 and -1 , with ascending gradations depending on worsening tibial nerve function. Those with complete loss of peroneal nerve function received a score ranging from 0 to +4 , with +4 reserved for those with the worst tibial nerve function. Gradations were subdivided as follows: 0 (normal tibial nerve function), 1 (electrophysiological findings of tibial nerve involvement only only), 2 (clinically mild tibial weakness but strong enough for tendon or nerve transfer), 3 (clinically significant tibial weakness eliminating possibility of immediate tendon or nerve transfer), and 4 (clinically significant tibial weakness permanently eliminating the possibility of nerve or tendon transfer).

\section{Statistical Analysis}

For each group, both the CPN and tibial nerve were segmented into 3 zones, and the amount of nerve injury was aggregated. The overall rate of nerve injury was analyzed between groups. The Student t-test was used to perform simple comparisons between Groups 1,2, and 3 for overall MRI nerve injury scores and subscores for the tibial nerve and CPN, independently, with $\mathrm{p}<0.05$ considered 


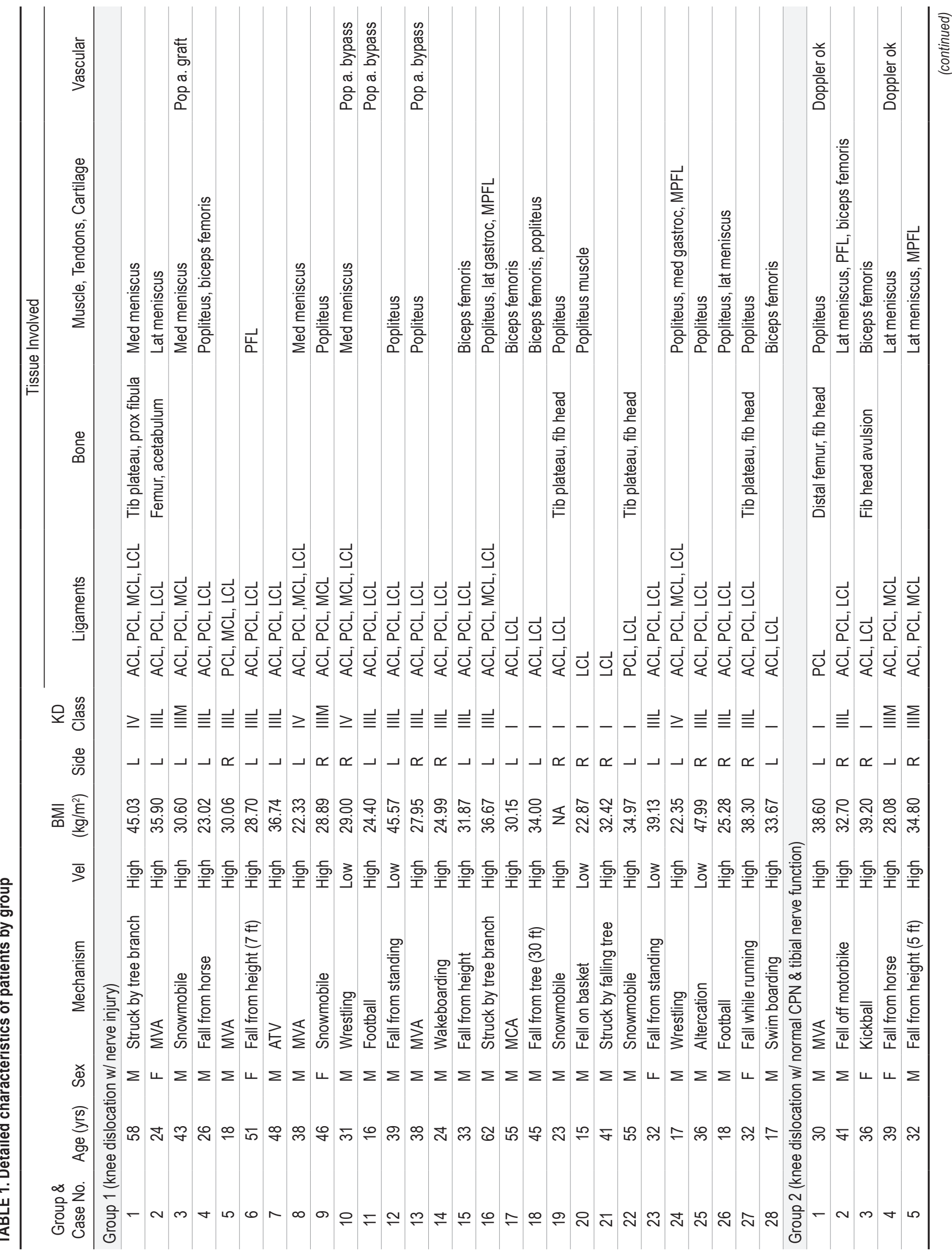




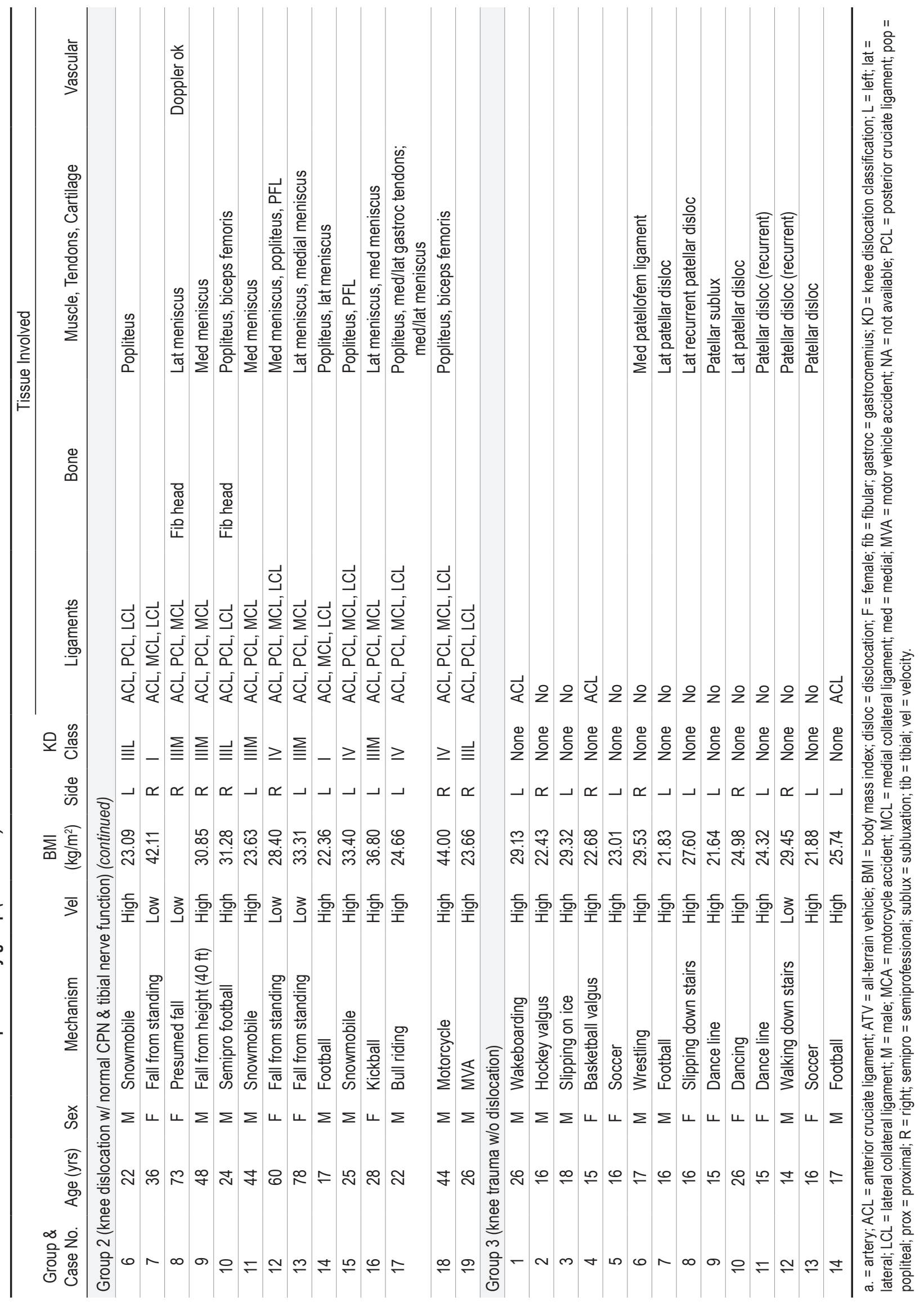


TABLE 2. Summary of patient characteristics by group

\begin{tabular}{|c|c|c|c|c|c|c|c|c|c|c|}
\hline Group & $\begin{array}{l}\text { No. of } \\
\text { Pts }\end{array}$ & $\begin{array}{l}\text { Age } \\
\text { (yrs) }\end{array}$ & $\begin{array}{c}\text { Sex } \\
(\% \mathrm{M})\end{array}$ & Mechanism of Injury & $\begin{array}{l}\text { High } \\
\text { Vel (\%) }\end{array}$ & $\begin{array}{c}\text { Mean BMI } \\
\left(\mathrm{kg} / \mathrm{m}^{2}\right)\end{array}$ & $\begin{array}{l}\text { Laterality } \\
\quad(\% \mathrm{~L})\end{array}$ & $\begin{array}{l}\text { KD Class } \\
\geq \text { III (\%) }\end{array}$ & $\begin{array}{l}\text { Ligaments } \\
(\% \mathrm{LCL})^{*}\end{array}$ & $\begin{array}{c}\text { Vascular } \\
(\%) \dagger\end{array}$ \\
\hline 1 & 28 & 35 & $82 \%$ & $\begin{array}{l}\text { Motorized, } 43 \% \text {; fall, } 29 \% \text {; } \\
\text { sports, } 18 \% \text {; tree- } \\
\text { related, } 11 \%\end{array}$ & $82 \%$ & 31.96 & $61 \%$ & $75 \%$ & $89 \%$ & $14 \%$ \\
\hline 2 & 19 & 38 & $63 \%$ & $\begin{array}{l}\text { Motorized, } 37 \% \text {; fall, } 37 \% \text {; } \\
\quad \text { sports, } 26 \%\end{array}$ & $79 \%$ & 31.72 & $47 \%$ & $79 \%$ & $58 \%$ & $0 \%$ \\
\hline 3 & 14 & 17 & $50 \%$ & $\begin{array}{l}\text { Sports, } 71 \% \text {; fall, } 21 \% \\
\quad \text { motorized, } 7 \%\end{array}$ & $93 \%$ & 25.25 & $64 \%$ & & & \\
\hline
\end{tabular}

statistically significant. Group 1 was further subdivided into cases of complete and partial peroneal nerve injuries, and within Group 1 a generalized linear model was used to create a multivariate model of the clinical score based on the MRI injury score for each zone and nerve to identify which zones of which nerves contributed significantly to the clinical score. Within Group 1, Pearson correlation was also performed between the MRI injury score and the clinical score, with significance again set at $\mathrm{p}<0.05$.

Combining the MRI injury scores of the 2 radiologists for each zone, a zone of maximum injury was identified for each nerve as the zone receiving the maximum combined MRI injury score, and these zones were compared within patients to see if simultaneous injury occurred preferentially in any of the 3 zones. For a given nerve, overlap for the site of maximum injury occurred when 2 zones had the same combined injury score, allowing both zones to be analyzed as zones of maximum injury.

\section{Results}

\section{Demographic and Injury Characteristics}

As can be seen in Tables 1 and 2, the characteristics between Groups 1 and 2 were well matched for age (35 vs 38 years, respectively), sex (82\% vs $63 \%$ male), percentage of high-velocity injuries (82\% in Group 1 vs $79 \%$ in Group 2), average BMI (31.96 vs $31.72 \mathrm{~kg} / \mathrm{m}^{2}$ ), laterality (61\% vs $47 \%$ left-sided), and severity of knee dislocation (KD) classification (75\% vs $79 \%$ KD III or higher). Group 3 , with minor knee trauma, had a different characteristic patient profile owing to a much lower age group (average age 17 years, $\mathrm{p}<0.001)$ and a much higher representation of sports-related injuries (71\% for Group 3 vs $18 \%$ for Group 1 and $26 \%$ for Group 2). This was in contrast to the rather high rates of injuries involving motorized vehicles (including snowmobiles, all-terrain vehicles, motorbikes, motocycles, and passenger vehicles) seen in Group 1 (43\%) and Group $2(37 \%)$ compared with Group $3(7 \%)$. BMI was also significantly lower in Group $3\left(25.25 \mathrm{~kg} / \mathrm{m}^{2}\right)$ relative to Group $1\left(31.96 \mathrm{~kg} / \mathrm{m}^{2}\right)$ and Group $2\left(31.72 \mathrm{~kg} / \mathrm{m}^{2}\right)$, at $\mathrm{p}<0.001$ for both comparisons. In those patients with knee dislocation, lateral collateral ligament (LCL) was more commonly involved in the group with clinical evidence of nerve injury (Group 1: 89\%) than those without nerve injury (Group 2: 58\%).

\section{Clinical Scores}

All 28 patients with clinical evidence of nerve injury (Group 1) had some degree of CPN involvement (Table 4). In these patients, tibial nerve function was always equal in MRC grade or better than peroneal nerve function. EMG was performed only in those with complete CPN palsy. Of those 19 patients, 2 did not undergo EMG. In 3 patients thought to have normal tibial nerve function, EMG was more sensitive than clinical examination (Group 1 Cases 19, 24, and 25) in detecting subtle deficits, increasing the clinical score from 0 to 1 .

\section{MRI Nerve Injury Scores}

The 2 radiologists were in exact agreement on all numerical scores $68 \%$ of the time. Specifically, for the 19 patients with complete CPN palsy (in Group 1), there was agreement on tibial nerve scoring $85 \%$ of the time and CPN scoring $77 \%$ of the time. When there was no agreement, the scoring of the senior radiologist was taken into account.

Nearly all of the nerve segments visualized in Groups 1 and 2 demonstrated some degree of injury on MRI (95\%). In Groups 1 and 2, diffuse injury was more common than focal injury, but focal injury, when present in any zone, was always associated with T2-weighted signal abnormality of the visualized nerve distal to the focal abnormality. In Group 3, by contrast, only $12 \%$ of nerve segments demonstrated radiological injury. Moreover, focal injuries were relatively more common, tended to be milder, and were not associated with any other T2-weighted signal abnormality in the remainder of the nerve.

MRI nerve injury scores were significantly more severe in Group 1 relative to Group 2 (2.06 vs 1.24, p < 0.001) and Group 2 relative to Group 3 (1.24 vs 0.13 , p < 0.001$)$. Knee dislocations were associated with higher MRI nerve injury scores than minor knee trauma $(1.73$ vs $0.13, \mathrm{p}<0.001)$. In both groups of patients with knee dislocations (Groups 1 and 2), MRI nerve injury score was significantly higher for the CPN than the tibial nerve (2.72 vs 1.40 for Group $1, \mathrm{p}<0.001 ; 1.39$ vs 1.09 for Group 2, $\mathrm{p}<0.05)$, and the overall respective significant difference between Groups 1 and 2 was driven more so by severe CPN injury (2.72 vs $1.39, \mathrm{p}<0.001)$ than by tibial nerve injury (1.40 vs $1.09, \mathrm{p}$ $<0.01$ ), although both were significant.

Within Group 1, those patients with complete CPN in- 


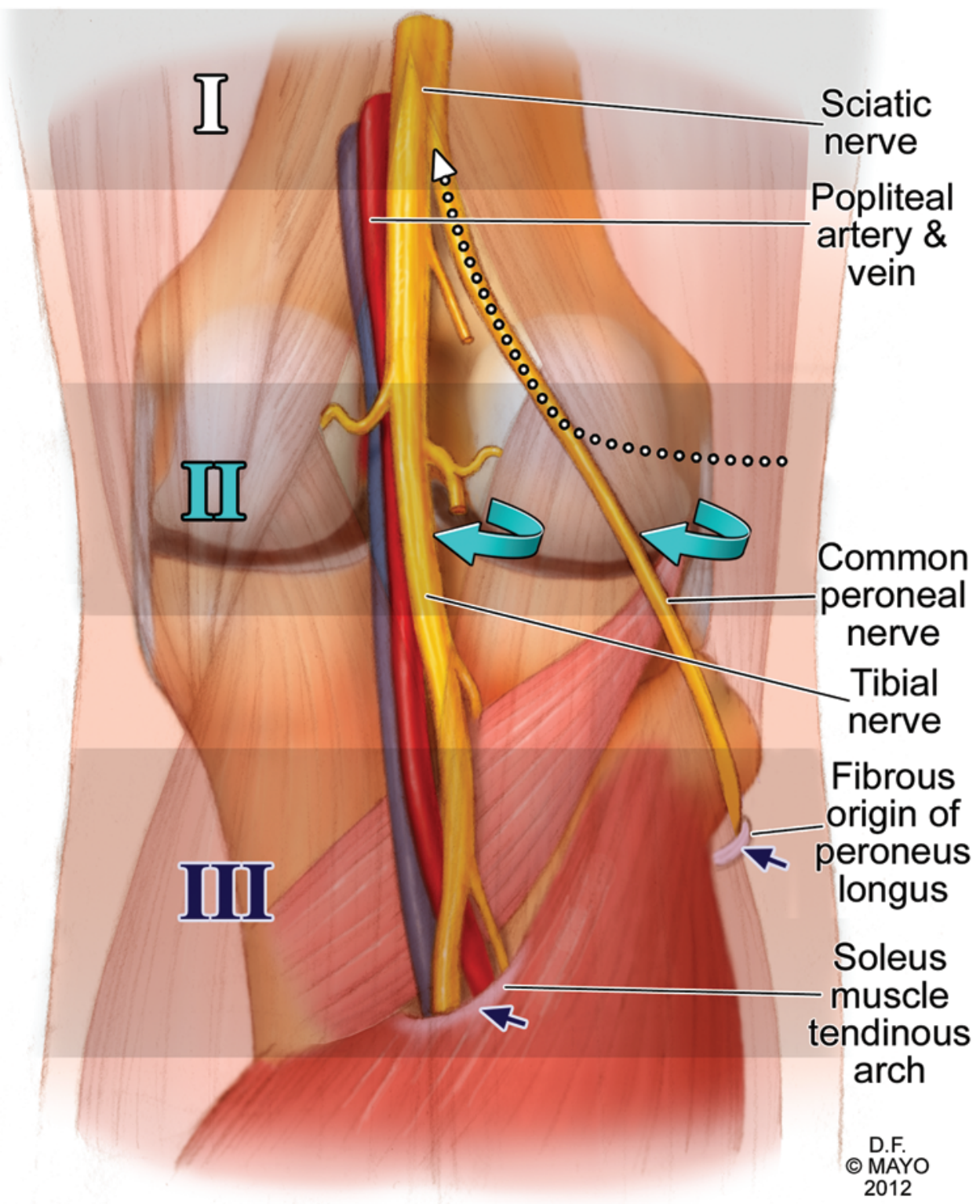

FIG. 1. Artist's illustration of a posterior view of the right knee showing the 3 purported zones of injury. In Zone I (white), the injury to both nerves occurs at the sciatic bifurcation, possibly through a torsion exerted by the CPN upon the bifurcation (white dotted arrow). In Zone II (cyan), traumatic dislocation of the knee joint results from a vector of force (curved arrow) that causes 2 separate injuries to the CPN and tibial nerve, independently. In Zone III (dark blue), the CPN is tethered at the fibrous origin of the peroneus longus, and the tibial nerve is tethered at the soleal sling, causing 2 separate injuries to the CPN and tibial nerve, independently. By permission of Mayo Foundation for Medical Education and Research. All rights reserved.

jury had significantly higher MRI injury scores than those with partial CPN injury (2.32 vs $1.52, \mathrm{p}<0.001)$, but this difference was driven by severity of CPN injury (3.17 vs $1.78, \mathrm{p}<0.001$ ) and not tibial nerve injury. Clinical injury score had a significantly strong correlation with MRI injury score of the CPN $(\mathrm{r}=0.75, \mathrm{p}<0.001)$ but not the tibial nerve $(r=0.07, p=0.83)$.

Using a generalized linear model, clinical injury score was significantly associated with Zone I CPN injury ( $\mathrm{p}=$ $0.0009)$, followed by Zone III tibial nerve injury $(p=0.02)$. In aggregate, there was no strong evidence for one zone of injury over another. For Groups 1 and 2, focal injuries of the tibial nerve were found in Zones I and II, and for the
CPN in all three zones. The MRI injury scores were fairly evenly distributed across zones in both groups. In Group I, the total of the MRI injury scores in Zone I represented $33 \%$ of the total number of points assigned in all 3 zones, and the totals for Zones II and III represented 37\% and $30 \%$, respectively. Similarly, in Group II, the total for Zone 1 represented $34 \%$ of the overall total, and the totals for Zones II and III represented $37 \%$ and $29 \%$, respectively.

\section{Discussion}

\section{Common Peroneal Nerve Injury}

Common peroneal nerve injury occurs in up to $25 \%-$ 

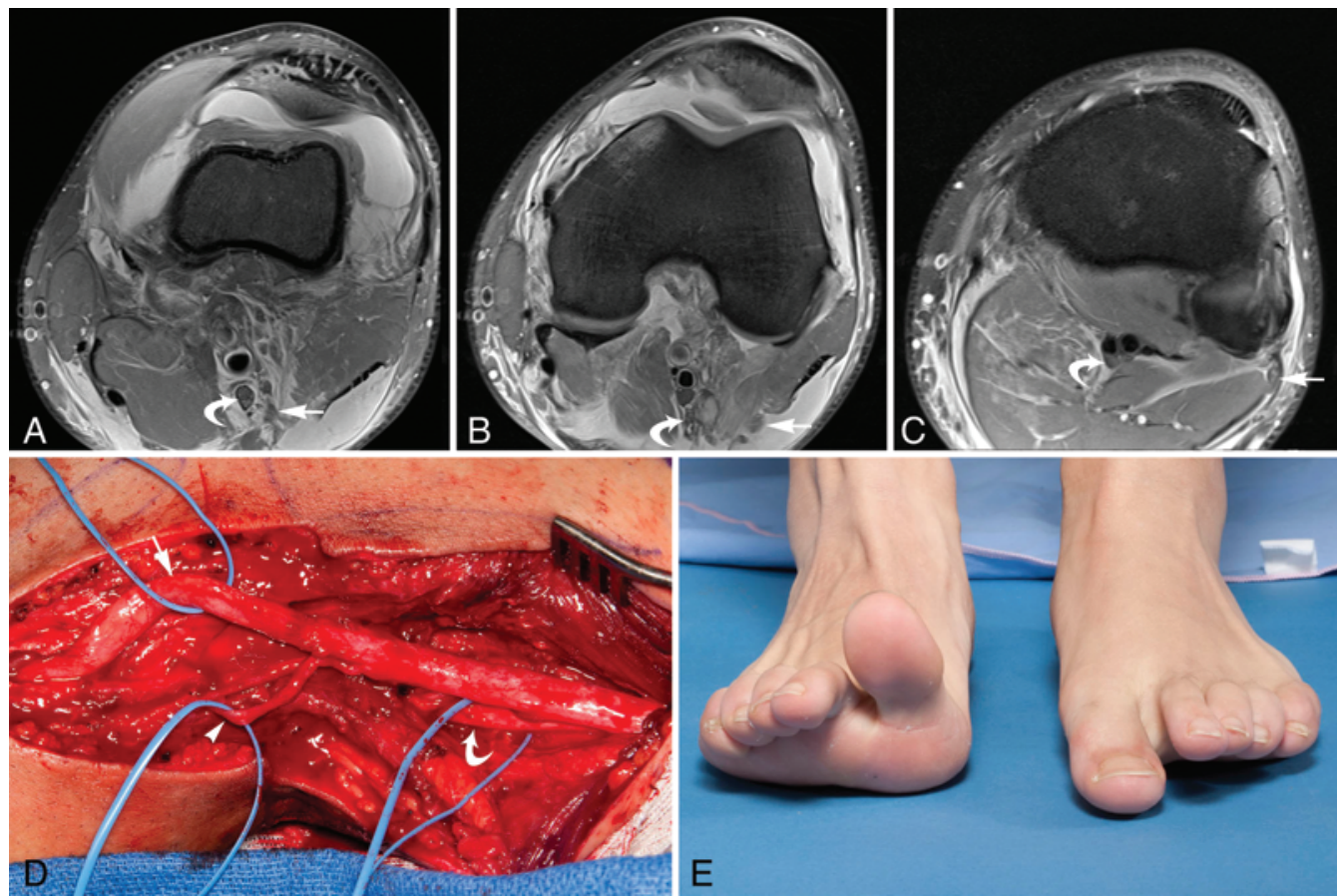

FIG. 2. Case 24 (Group 1). Preoperative axial proton density T2-weighted fat-suppressed MR images of the left knee progressing from superior to inferior (A to B to C), with an intraoperative photograph (D) and clinical photograph of both feet at 1 year after surgery (E). The course of the tibial nerve (curved arrow) and CPN (straight arrow) is visualized through the 3 zones of injury progressing from $A$ to $B$ to $C$. This patient had complete CPN palsy and clinically normal tibial nerve function. MRI shows diffuse Grade 2 injury of the tibial nerve throughout all 3 zones and Grade 4 injury of the CPN throughout all 3 zones. Intraoperative exploration actually demonstrated anatomical and electrophysiological continuity of the CPN with intact nerve action potentials conducting across the peroneal nerve just distal to the sural nerve branch (arrowhead). At the 1-year follow-up evaluation (E), the patient had partial return of peroneal function in the left foot relative to the normal right foot (shown for comparison).

$40 \%$ of patients with knee dislocations., ${ }^{4,510,15}$ Nearly onehalf of patients with nerve involvement may have a permanent deficit, and results of surgical repair have typically been modest, especially with longer grafts. ${ }^{11,15,19,23,26,30}$ Increased prevalence of CPN palsy is associated with higher velocity injury mechanisms, ${ }^{5,21}$ knee dislocations with posterior cruciate ligament and posterolateral corner injuries, ${ }^{15}$ and increased BMI. ${ }^{16,21}$
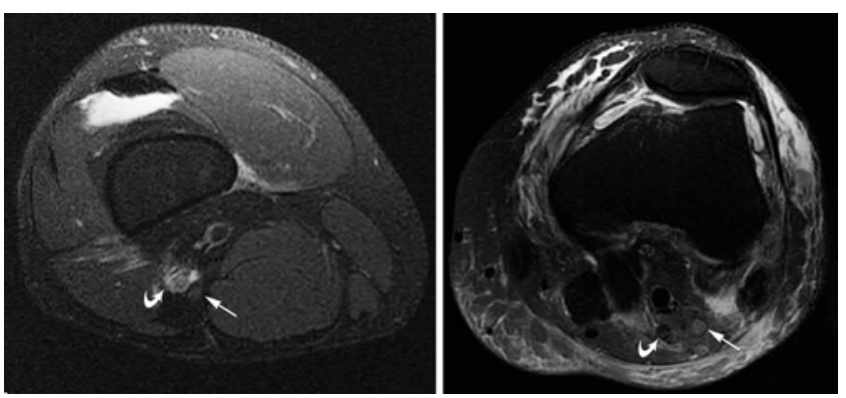

FIG. 3. Left: Case 21 (Group 1). Axial T2-weighted fat-suppressed MR image of the right knee at the sciatic bifurcation (Zone I) showing diffuse MRC Grade 1 injury of the tibial nerve (straight arrow) and focal MRC Grade 3 injury of the CPN (curved arrow) with focal hemorrhage. This patient had complete CPN palsy with MRC Grade 4 tibial nerve function. Right: Case 1 (Group 1). Axial T2-weighted fat-suppressed MR image of the left knee at the knee joint (Zone II) showing focal MRC Grade 3 injury of both the tibial nerve (curved arrow) and CPN (straight arrow). This patient had MRC Grade 4 function in both the tibial and peroneal nerve distributions.

\section{Demographic and Injury Characteristics}

Based on the demographic characteristics of our patients and the mechanisms of injury, our study was consistent with the literature. In the groups with knee dislocation compared with the group with only minor knee trauma, there was a higher percentage of motorized mechanisms of injury (43\% in Group 1 and 37\% in Group 2 vs 7\% in Group 3), compared with a preponderance of sports-related injuries in Group 3 (73\%). BMI was significantly higher in Group $1\left(31.96 \mathrm{~kg} / \mathrm{m}^{2}\right)$ and Group $2\left(31.72 \mathrm{~kg} / \mathrm{m}^{2}\right)$ relative to Group $3\left(25.25 \mathrm{~kg} / \mathrm{m}^{2}\right)$. Interestingly, in our study there were no significant differences in terms of BMI or percentage of motorized or high-energy injury between those knee dislocation patients manifesting clinical evidence of nerve injury (Group 1) and those who did not (Group 2).

\section{Tibial Nerve Injury}

The prevalence of tibial nerve injury after knee dislocation is much lower, with few reports in the literature. . $^{10,12,22,23}$ When tibial nerve injury does occur, it is always reported with concomitant CPN injury. ${ }^{2,12,22,25}$ Typically, these combined injuries are secondary to higher-energy trauma. In this regard, our study was also in keeping with the literature. In our series of Group 1 patients, all 15 of the 28 patients who had some degree of tibial nerve injury had concomitant CPN injury that was always at least as severe as the tibial nerve injury, and $80 \%$ of these patients had a high-energy injury. 


\section{G. Reddy et al.}

Relatively more severe injury to the CPN rather than the tibial nerve has been attributed to anatomical differences between the two. The CPN has a relatively fixed attachment at the fibular neck, which makes it susceptible to stretch due to relative fixation, especially when the knee is subjected to varus and hyperextension forces. Simultaneously, the nerve in this location is also superficial and vulnerable to direct external compression. The tibial nerve, by contrast, lies deep in the posterior compartment of the leg and is untethered along its course. Sunderland also described less supportive connective tissue and fewer autonomic fibers, which make the CPN more susceptible to traction injury than the tibial nerve., 40,26

\section{Surgical Repair}

Degree of tibial nerve injury has implications for the surgical repair options regarding the CPN. With a goal toward achieving independence from an ankle-foot orthosis, surgical options have included peroneal nerve neurolysis and/or grafting, transfer of a branch of the tibial nerve into the deep peroneal nerve,${ }^{1,8}$ or posterior tibial tendon transfer to the tibialis anterior tendon (Bridle procedure $\left.{ }^{13,17}\right) .5,9$ Abiding by the principle that transferred nerves and tendons typically lose 1 grade of strength, patients with severe tibial nerve weakness are not suitable candidates for either nerve or tendon transfer. Nevertheless, results from peroneal nerve neurolysis and/or grafting have typically been disappointing, diminishing with longer graft lengths. ${ }^{11,15,19,23,26,30}$ Given the capacity of the tibial nerve to improve over time and the lack of a time limit on the tendon transfer operation, the Bridle procedure has remained a very reliable fallback treatment in cases of poor peroneal recovery. The tendon transfer procedure is so successful that some surgeons have advocated performing the Bridle procedure at the same time as the peroneal nerve repair. ,, $714^{7}$ Timing considerations must also be given to repair of the knee ligaments. ${ }^{9}$

\section{Knee Dislocations}

Knee dislocations have been classically characterized by energy level of injury, joint position, and anatomical ligamentous disruption. Owing to the fact that a majority of knee dislocations are spontaneously reduced before medical evaluation, we chose to adopt the energy level of dislocation and anatomical "knee dislocation" score devised by Schenck..$^{18}$ In this scoring system, CPN palsy is more commonly seen with KD IIIL injuries (both cruciates, posterolateral corner torn). KD IV injuries are highly unstable and typically seen in high-energy trauma. ${ }^{15}$

With respect to knee dislocation also, our findings were in keeping with fully $75 \%$ of the patients in Group 1 and $79 \%$ of the patients in Group 2 manifesting a KD classification of KD III or higher. In those patients with knee dislocation, the LCL was more commonly involved in the group with clinical evidence of nerve injury (Group $1,89 \%$ ) than those without nerve injury (Group 2, 58\%). With high-energy injury, vascular injury is also often seen in combination with nerve injury. ${ }^{2,3,10,21}$ In Group 1, 4 of the

TABLE 3. MRI and clinical assessment criteria*

\begin{tabular}{|c|c|}
\hline $\begin{array}{l}\text { Score or Letter } \\
\text { Grade }\end{array}$ & Criteria \\
\hline \multicolumn{2}{|l|}{ MRI evaluation* } \\
\hline 1 & Mild T2 hyperintensity \\
\hline 2 & Moderate T2 hyperintensity \\
\hline 3 & Severe T2 hyperintensity or focal hemorrhage w/in the nerve \\
\hline 4 & Very severe injury or appearance of discontinuity, rupture, or transection. \\
\hline $\mathrm{F}$ & Focal injury ( $\leq 5 \mathrm{~mm}, 1$ imaging slice thickness) \\
\hline $\mathrm{D}$ & Diffuse injury ( $\geq 1 \mathrm{~cm}$, multiple contiguous slices) \\
\hline $\mathrm{R}$ & Rupture (very severe injury, unrecognizable nerve) \\
\hline $\mathrm{N}$ & Normal \\
\hline \multicolumn{2}{|l|}{ Clinical evaluation } \\
\hline-4 & CPN normal (MRC 5), tibial nerve normal (MRC 5) \\
\hline-3 & CPN weak (MRC 4), tibial nerve normal (MRC 5) \\
\hline-2 & CPN weak (MRC 3-4), tibial nerve weak (MRC 3-4) \\
\hline-1 & CPN very weak (MRC 1-2), tibial nerve normal \\
\hline 0 & CPN out (MRC 0), tibial nerve normal clinically (MRC 5) \& on EMG \\
\hline 1 & $\begin{array}{l}\text { CPN out (MRC 0), tibial nerve clinically normal (MRC 5), but EMG shows involvement of tibial nerve inner- } \\
\text { vated muscles }\end{array}$ \\
\hline 2 & CPN out (MRC 0), tibial nerve weak (MRC 4) but strong enough for Bridle procedure \\
\hline 3 & $\begin{array}{l}\text { CPN out (MRC 0), tibial nerve weak (MRC } 3 \text { ) \& not strong enough for Bridle at present, but potential for fu- } \\
\text { ture recovery }\end{array}$ \\
\hline 4 & CPN out (MRC 0), tibial nerve (MRC 1-2) will likely not be strong enough for Bridle at any time \\
\hline
\end{tabular}




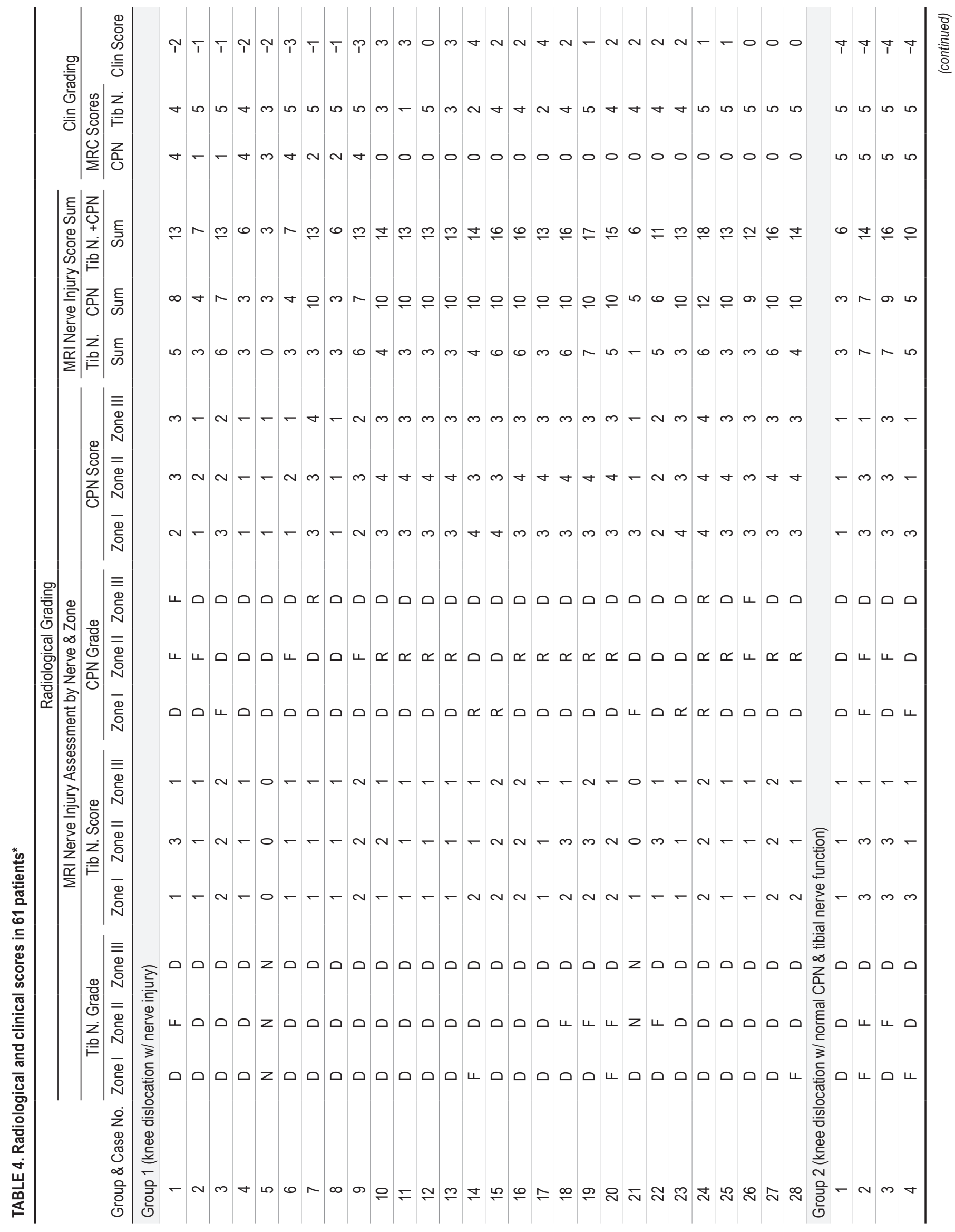




\section{G. Reddy et al.}

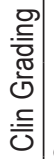

등

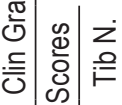

品总

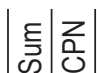

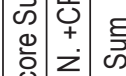

की

조

高吾 $\frac{E}{D}$

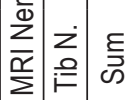

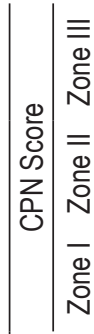

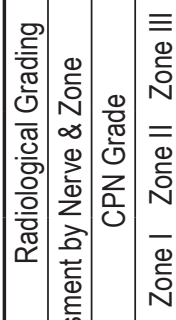

ญे

造

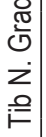

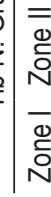

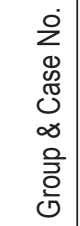

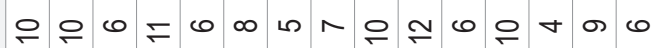

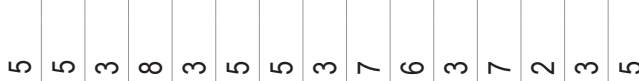

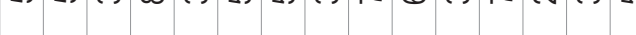

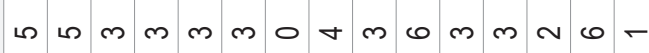

$-a m-m--m n-m 0-n$

$n n-m-t m-m n-m-r$

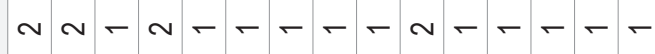

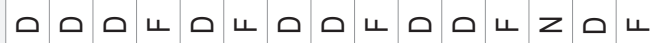

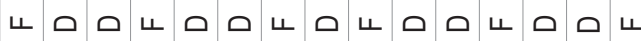

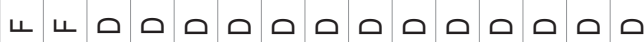

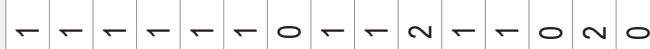

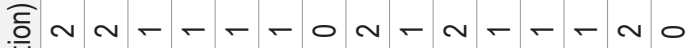

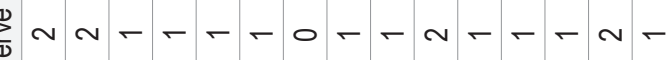

$00 n 0-0-0000000$

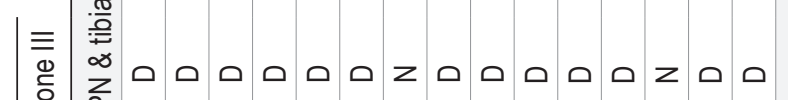

ह

등

$0-m 0 n 0 n 0000000$

$0-6-0-0000000$

00 n $-0-0000000$

00000000000000

00000000000000

$0-r 0-0-0000000$

$z 00 z z z z z z z z z z z$

$z 00 z z z z z z z z z z z$

$z \sqcup 4 z \leftarrow z \leftarrow z z z z z z z$

00000000000000

00000000000000

0 nor-oro000000

$z z z z z z z z z z z z$ 产

$z z z z z z z z z z z z$ $\frac{0}{3} z z$ z $z$ z zzzzzz

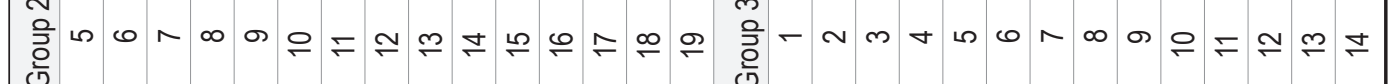


28 patients had popliteal artery occlusion requiring bypass grafting (all 4 had KD III or higher), whereas none of the patients in Group 2 had a vascular injury requiring repair.

\section{MRI Appearance of Nerve Injury}

MRI is very sensitive for detecting nerve injury, even in those patients without clinical evidence of nerve injury. Nearly all of the nerve segments visualized in Groups 1 and 2 demonstrated some degree of injury on MRI (95\%) as determined by the fascicular architecture and T2weighted signal increase within the nerves. Consistent with the concept of higher-energy injuries involved in Groups 1 and 2, diffuse injury was more common than focal injury. When focal injury was present in these groups, however, it was always associated with abnormal signal in the visualized distal nerve. By contrast, in Group 3, only $12 \%$ of nerve segments demonstrated any degree of injury. Moreover, focal injuries were more common in this group, but tended to be milder and were not associated with any injury to the remainder of the nerve.

MRI demonstrated severe injury scores even in those patients who were clinically deemed to have normal function (Group 2) and those patients who had normal tibial nerve distribution EMG results (Group 1, Cases 26-28), suggesting MRI is even more sensitive than EMG for detection of subclinical nerve injury.

As a counterargument, however, MRI injury score did highly correlate with the clinical degree of CPN injury ( $\mathrm{r}$ $=0.75, \mathrm{p}<0.001)$ but not with tibial nerve injury $(\mathrm{r}=0.07$, $\mathrm{p}=0.83$ ), either by MRC scoring or the composite clinical score. MRI nerve injury scores were significantly more severe in Group 1 relative to Group 2 (2.06 vs 1.24, p < 0.001 ) and Group 2 relative to Group 3 (1.24 vs 0.13 , p < 0.001). Within Group 1, those patients with complete CPN injury had significantly higher MRI injury scores than those with partial CPN injury (2.32 vs $1.52, \mathrm{p}<0.001)$, but this difference was driven by severity of CPN injury (3.17 vs $1.78, \mathrm{p}<0.001)$ and not tibial nerve injury (1.46 vs 1.26 , $\mathrm{p}=0.22)$.

Knee dislocations were associated with higher MRI nerve injury scores than minor knee trauma (1.73 vs 0.13 , $p$ $<0.001)$. In both groups of patients with knee dislocations (Groups 1 and 2), MRI nerve injury score was significantly higher for peroneal nerve than tibial nerve (2.72 vs 1.40 for Group 1, p < 0.001; 1.39 vs 1.09 for Group 2, p < 0.05), and the overall respective significant difference between Groups 1 and 2 was driven by more severe CPN injury (2.72 vs $1.39, \mathrm{p}<0.001)$ rather than tibial nerve injury $(1.40$ vs $1.09, \mathrm{p}<0.01)$, although both were significant.

In terms of clinical significance, patients with knee dislocations with severe ligamentous injury typically require an MRI for operative planning purposes for repair of knee ligaments. These MR images can be further studied to evaluate the degree of CPN and tibial nerve injury. Our study suggests that MRI may be more sensitive than EMG in detecting subclinical nerve injuries. With regard to nerve injuries that require operative intervention, however, clinical examination supported by electrodiagnostic testing remains the gold standard. The level of nerve injury requiring operative repair would be clinically detectable well above the sensitivity threshholds of both EMG and MRI.
Therefore, in clinical practice, we do not routinely advocate a dedicated MRI study to evaluate the nerves if sufficient information has been gleaned from clinical examination and additional electrodiagnostic tests. If, however, existing MRI suggests subclinical damage to the tibial nerve in a patient scheduled for operative repair, the clinical examiner may be more vigilant in the assessment of donor tibial nerve function prior to tendon or nerve transfer. Moreoever, if the surgeon is planning direct repair or grafting of the peroneal nerve, a more severe or diffuse MRI injury score might sway the surgeon toward earlier or simultaneous tendon transfer, in cases of long-segment damage or failed results. Study of the existing MRI appearance of nerve injury may provide supplementary information that is valuable in preoperative planning, but the current study was not focused on degree of injury and recovery of nerve function over time as correlated with MRI.

\section{Zones of Injury}

Using a generalized linear model, clinical injury score was significantly associated with Zone I CPN injury $(\mathrm{p}=$ $0.0009)$, followed by Zone III tibial nerve injury ( $\mathrm{p}=0.02)$. In Groups 1 and 2, focal injuries of the tibial nerve were found in Zones I and II; focal injuries of the CPN were found in all 3 zones. There was no clear pattern favoring one zone relative to another.

In Group 1, the total MRI injury scores were fairly evenly distributed across zones (Zone I, 33\% of overall total; Zone II, 37\%; Zone III, 30\%). In Group 2, they were also similarly distributed (Zone I, 34\%; Zone II, 37\%; Zone III, 29\%). The point of maximum injury occurs with similar frequency in each of the 3 zones, suggesting that, while in some cases a single longitudinal stretch of the CPN back to the sciatic bifurcation may account for both injuries, in the majority of cases the injury to each nerve occurs independently.

Some authors have described the soleal sling as a potential zone of compression of the tibial nerve. ${ }^{27-29}$ Tibial nerve injury in Zone III, i.e. the soleal sling, did emerge as one of the zones independently associated with the clinical score. Nevertheless, the point of maximum injury was distributed relatively evenly across all 3 zones for both Group 1 and Group 2, suggesting that routine decompression of the tibial nerve at the soleal sling and the peroneal nerve at the fibular neck be considered on a case-by-case basis.

\section{Conclusions}

Subclinical neural injury following knee dislocation is relatively common. Knee dislocation is associated with a significantly higher MRI nerve injury score than is seen in minor knee trauma. Combining the high sensitivity of the MRI injury signal and strong correlation between injury signal and clinical peroneal function, the authors suggest that MRI may be an adjunct to clinical evaluation and electrodiagnostic studies when planning to surgically address correction of foot drop in individuals with CPN palsy. In assessing tibial nerve function, clinical examination remains the gold standard. With knee dislocations, the results of our study support the notion that clinical tibial nerve injury is always associated with simultaneous 
CPN nerve injury and tibial nerve function is never worse than peroneal nerve function. The point of maximum injury occurs with similar frequency in each of the 3 zones, suggesting that, while in some cases a single longitudinal stretch of the CPN back to the sciatic bifurcation may account for both injuries, in the majority of cases the injury to each nerve occurs independently.

\section{Acknowledgments}

We would like to thank Dave Factor for assistance with illustration and Peggy Chihak for assistance with generation of the figures.

\section{References}

1. Bodily KD, Spinner RJ, Bishop AT: Restoration of motor function of the deep fibular (peroneal) nerve by direct nerve transfer of branches from the tibial nerve: an anatomical study. Clin Anat 17:201-205, 2004

2. Bonnevialle P, Chaufour X, Loustau O, Mansat P, Pidhorz L, Mansat M: [Traumatic knee dislocation with popliteal vascular disruption: retrospective study of 14 cases.] Rev Chir Orthop Reparatrice Appar Mot 92:768-777, 2006 (Fr)

3. Bonnevialle P, Pidhorz L, Membres du Groupe d'Étude en Traumatologie Ostéoarticulaire: [Dislocation and fractures around the knee with popliteal artery injury: A retrospective analysis of 54 cases.] Rev Chir Orthop Reparatrice Appar Mot 92:508-516, 2006 (Fr)

4. Cho D, Saetia K, Lee S, Kline DG, Kim DH: Peroneal nerve injury associated with sports-related knee injury. Neurosurg Focus 31(5):E11, 2011

5. Cush G, Irgit K: Drop foot after knee dislocation: evaluation and treatment. Sports Med Arthrosc Rev 19:139-146, 2011

6. Ferraresi S, Garozzo D, Buffatti P: Common peroneal nerve injuries: results with one-stage nerve repair and tendon transfer. Neurosurg Rev 26:175-179, 2003

7. Garozzo D, Ferraresi S, Buffatti P: Surgical treatment of common peroneal nerve injuries: indications and results. A series of 62 cases. J Neurosurg Sci 48:105-112, 2004

8. Giuffre JL, Bishop AT, Spinner RJ, Levy BA, Shin AY: Partial tibial nerve transfer to the tibialis anterior motor branch to treat peroneal nerve injury after knee trauma. Clin Orthop Relat Res 470:779-790, 2012

9. Giuseffi SA, Bishop AT, Shin AY, Dahm DL, Stuart MJ, Levy BA: Surgical treatment of peroneal nerve palsy after knee dislocation. Knee Surg Sports Traumatol Arthrosc 18:1583-1586, 2010

10. Johnson ME, Foster L, DeLee JC: Neurologic and vascular injuries associated with knee ligament injuries. Am J Sports Med 36:2448-2462, 2008

11. Kim DH, Murovic JA, Tiel RL, Kline DG: Management and outcomes in 318 operative common peroneal nerve lesions at the Louisiana State University Health Sciences Center. Neurosurgery 54:1421-1428, discussion 1428-1429, 2004

12. Malizos KN, Xenakis T, Mavrodontidis AN, Xanthis A, Korobilias AB, Soucacos PN: Knee dislocations and their management. A report of 16 cases. Acta Orthop Scand Suppl 275:80-83, 1997

13. McCall RE, Frederick HA, McCluskey GM, Riordan DC: The Bridle procedure: a new treatment for equinus and equinovarus deformities in children. J Pediatr Orthop 11:83-89, 1991

14. Millessi H: Lower extremity nerve lesions, in Terzis JK (ed): Microreconstruction of Nerve Injuries. Philadelphia: WB Saunders, 1987, pp 239-251

15. Niall DM, Nutton RW, Keating JF: Palsy of the common pe- roneal nerve after traumatic dislocation of the knee. J Bone Joint Surg Br 87:664-667, 2005

16. Peltola EK, Lindahl J, Hietaranta H, Koskinen SK: Knee dislocation in overweight patients. AJR Am J Roentgenol 192:101-106, 2009

17. Rodriguez RP: The Bridle procedure in the treatment of paralysis of the foot. Foot Ankle 13:63-69, 1992

18. Schenck R Jr: Classification of knee dislocations. Oper Tech Sports Med 11:193-198, 2003

19. Sedel L, Nizard RS: Nerve grafting for traction injuries of the common peroneal nerve. A report of 17 cases. J Bone Joint Surg Br 75:772-774, 1993

20. Sunderland S: Nerve and Nerve Injuries. Edinburgh: Churchill Livingstone, 1972

21. Tay AK, MacDonald PB: Complications associated with treatment of multiple ligament injured (dislocated) knee. Sports Med Arthrosc Rev 19:153-161, 2011

22. Terzis JK, Kostopoulos VK: Vascularized nerve grafts for lower extremity nerve reconstruction. Ann Plast Surg 64:169-176, 2010

23. Tomaino M, Day C, Papageorgiou C, Harner C, Fu FH: Peroneal nerve palsy following knee dislocation: pathoanatomy and implications for treatment. Knee Surg Sports Traumatol Arthrosc 8: 163-165, 2000

24. Trappeniers L, De Maeseneer M, Van Roy P, Chaskis C, Osteaux M: Peroneal nerve injury in three patients with knee trauma: MR imaging and correlation with anatomic findings in volunteers and anatomic specimens. Eur Radiol 13:17221727,2003

25. Wascher DC, Dvirnak PC, DeCoster TA: Knee dislocation: initial assessment and implications for treatment. J Orthop Trauma 11:525-529, 1997

26. Wilkinson MC, Birch R: Repair of the common peroneal nerve. J Bone Joint Surg Br 77:501-503, 1995

27. Williams EH, Rosson GD, Hagan RR, Hashemi SS, Dellon AL: Soleal sling syndrome (proximal tibial nerve compression): results of surgical decompression. Plast Reconstr Surg 129:454-462, 2012

28. Williams EH, Williams CG, Rosson GD, Dellon AL: Combined peroneal and proximal tibial nerve palsies. Microsurgery 29:259-264, 2009

29. Williams EH, Williams CG, Rosson GD, Dellon LA: Anatomic site for proximal tibial nerve compression: a cadaver study. Ann Plast Surg 62:322-325, 2009

30. Wood MB: Peroneal nerve repair. Surgical results. Clin Orthop Relat Res (267):206-210, 1991

\section{Disclosure}

The authors report no conflict of interest concerning the materials or methods used in this study or the findings specified in this paper.

\section{Author Contributions}

Conception and design: Reddy, Spinner. Acquisition of data: Reddy. Analysis and interpretation of data: Reddy, Amrami, Howe. Drafting the article: Reddy, Spinner. Critically revising the article: all authors. Reviewed submitted version of manuscript: Reddy, Spinner. Approved the final version of the manuscript on behalf of all authors: Reddy. Statistical analysis: Reddy. Administrative/technical/material support: Reddy, Spinner. Study supervision: Spinner.

\section{Correspondence}

Chandan G. Reddy, Department of Neurosurgery, University of Iowa Hospitals and Clinics, 200 Hawkins Dr., Ste. 1829 JPP, Iowa City, IA 52242. email: chandan-reddy@uiowa.edu. 